\title{
Dimensional characterization of heat flux in aquifers with horizontal water flow. Velocity estimation from temperature-depth profiles
}

\author{
José Antonio Valera ${ }^{1}$ and Francisco Alhama ${ }^{1}$ \\ ${ }^{1}$ Universidad Politécnica de Cartagena
}

July 5,2021

\begin{abstract}
From the dimensionless governing equations obtained through an adequate selection of dependent and independent dimensionless variables, and the use of spatial discrimination, the dimensionless groups that govern the solution patterns of the heat transfer problem in aquifers with horizontal flow velocity are determined. As a boundary condition on the surface, the cases of constant and harmonic temperature are studied. The emergence of a characteristic length that, in its dimensionless form, depends on the deduced groups, allows the direct determination of the water flow from experimental measurements of the temperature profiles in the classical form of the inverse problem.
\end{abstract}

\section{Hosted file}

Dimensional characterization of heat flux in aquifers with horizontal water flow. Velocity estimation f available at https://authorea.com/users/423830/articles/529061-dimensional-characterizationof-heat-flux-in-aquifers-with-horizontal-water-flow-velocity-estimation-fromtemperature-depth-profiles

\section{Hosted file}

TABLE 1.docx available at https://authorea.com/users/423830/articles/529061-dimensionalcharacterization-of-heat-flux-in-aquifers-with-horizontal-water-flow-velocityestimation-from-temperature-depth-profiles

\section{Hosted file}

TABLE 2.docx available at https://authorea.com/users/423830/articles/529061-dimensionalcharacterization-of-heat-flux-in-aquifers-with-horizontal-water-flow-velocityestimation-from-temperature-depth-profiles

\section{Hosted file}

TABLE 3.docx available at https://authorea.com/users/423830/articles/529061-dimensionalcharacterization-of-heat-flux-in-aquifers-with-horizontal-water-flow-velocityestimation-from-temperature-depth-profiles

\section{Hosted file}

TABLE 4.docx available at https://authorea.com/users/423830/articles/529061-dimensionalcharacterization-of-heat-flux-in-aquifers-with-horizontal-water-flow-velocityestimation-from-temperature-depth-profiles 
$\mathrm{T}_{1}$

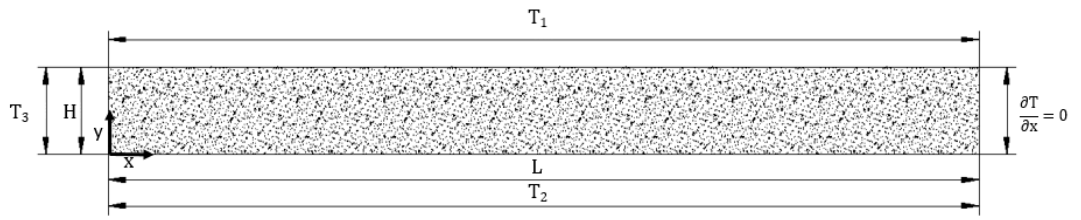

Figure 1. Physical scheme of the problem and boundary conditions
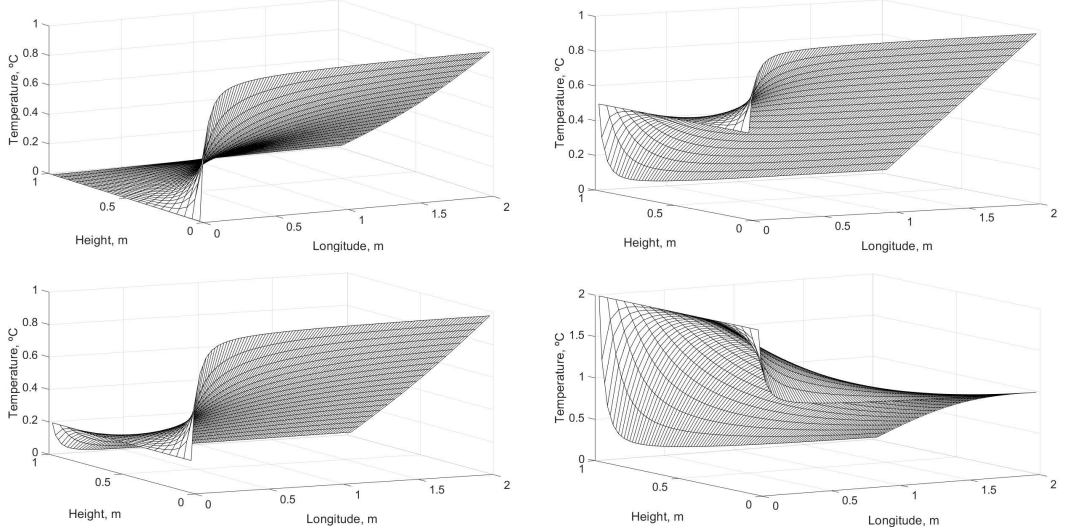

Figure 2. Patterns of the steady-state solution for the scenarios of Table 1. Scenarios I and II (up) and Scenarios III and IV (down) 


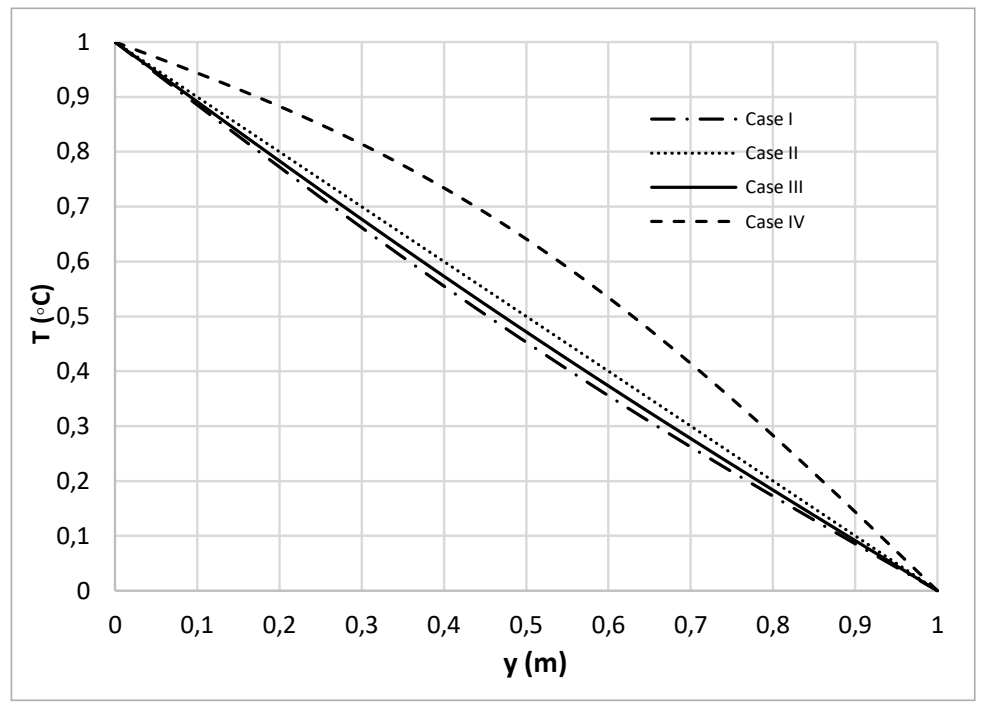

Figure 3. Temperature profiles at $x=2 \mathrm{~m}$ for the Scenarios of Table 1
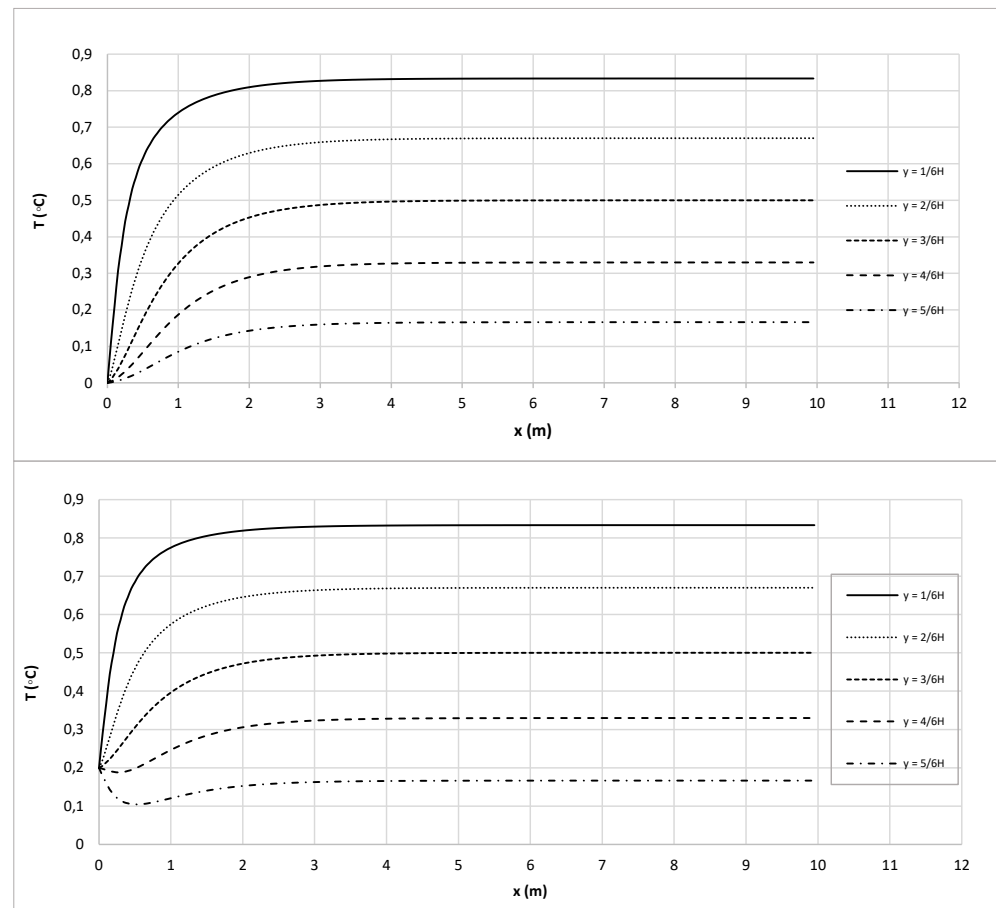

Figure 4. Steady-state, horizontal temperature profiles of Scenarios I (up) and III (down) at $y=\frac{H}{6}, \frac{2 \mathrm{H}}{6}, \frac{3 \mathrm{H}}{6}, \frac{4 \mathrm{H}}{6}$ and $\frac{5 \mathrm{H}}{6}$ 


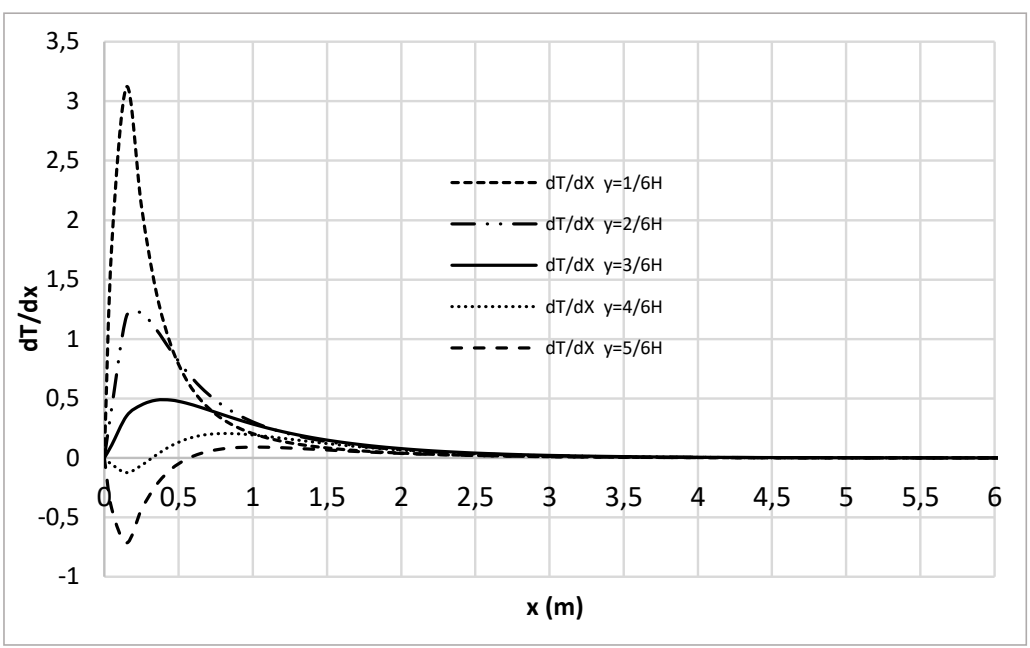

Figure 5. Values of $\partial \mathrm{T} / \partial \mathrm{x}$ for Scenario III at $\mathrm{y}=\frac{\mathrm{H}}{6}, \frac{2 \mathrm{H}}{6}, \frac{3 \mathrm{H}}{6}, \frac{4 \mathrm{H}}{6}$ and $\frac{5 \mathrm{H}}{6} \mathrm{~m}$

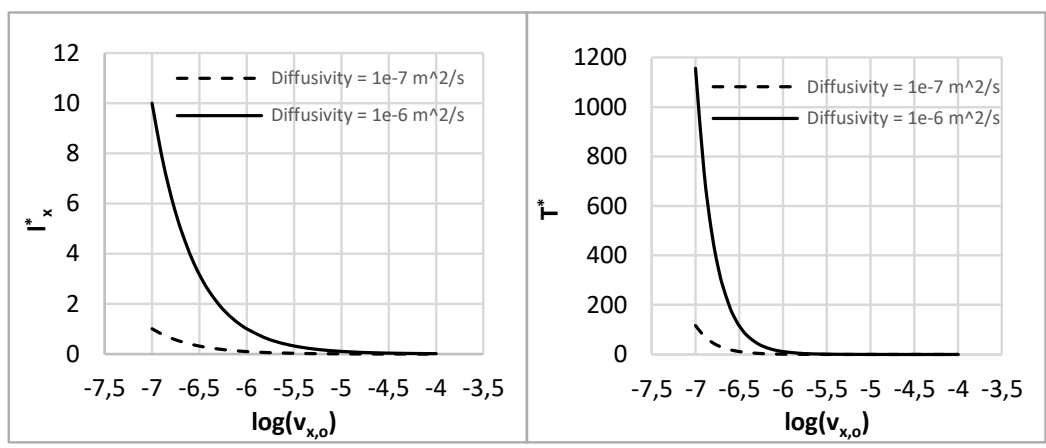

Figure 6. Dependences $\mathrm{l}_{\mathrm{x}}^{*}-\log \left(\mathrm{v}_{\mathrm{x}, \mathrm{o}}\right)$ and $\tau^{*}-\log \left(\mathrm{v}_{\mathrm{x}, \mathrm{o}}\right)$ 


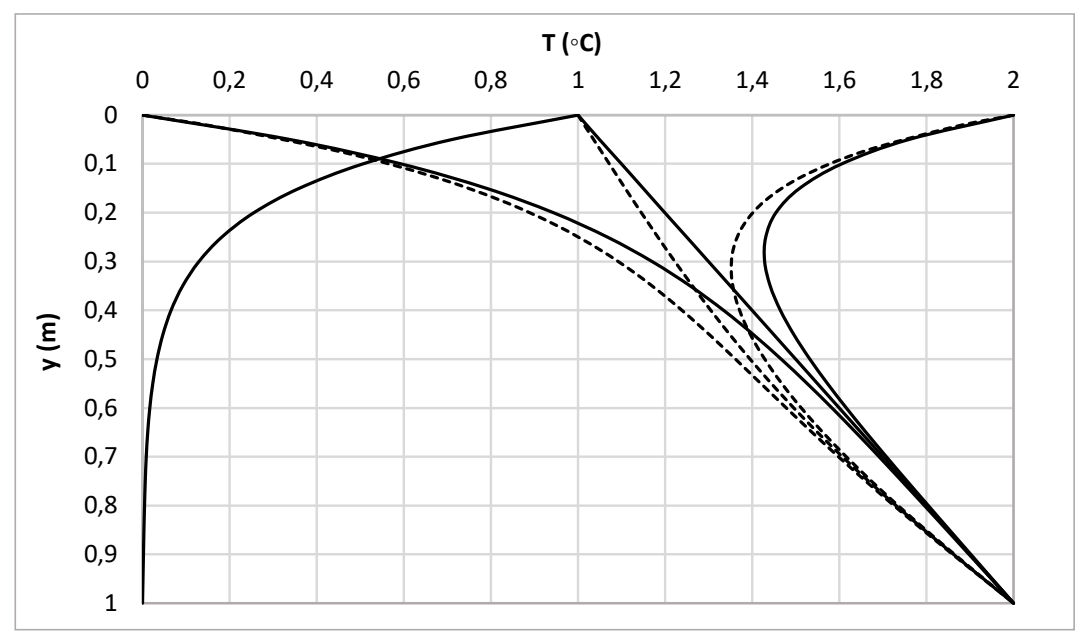

Figure 7. Involutes of $T_{\max }$ and $\left(T_{\min }\right),\left(T_{a v}\right)$ and deviations $\left(T_{\max }-T_{\min }\right) / 2$ as a function of depth. $x=1 \mathrm{~m}$ (dashed lines) and $\mathrm{x}=20 \mathrm{~m}$ (continuous lines). 

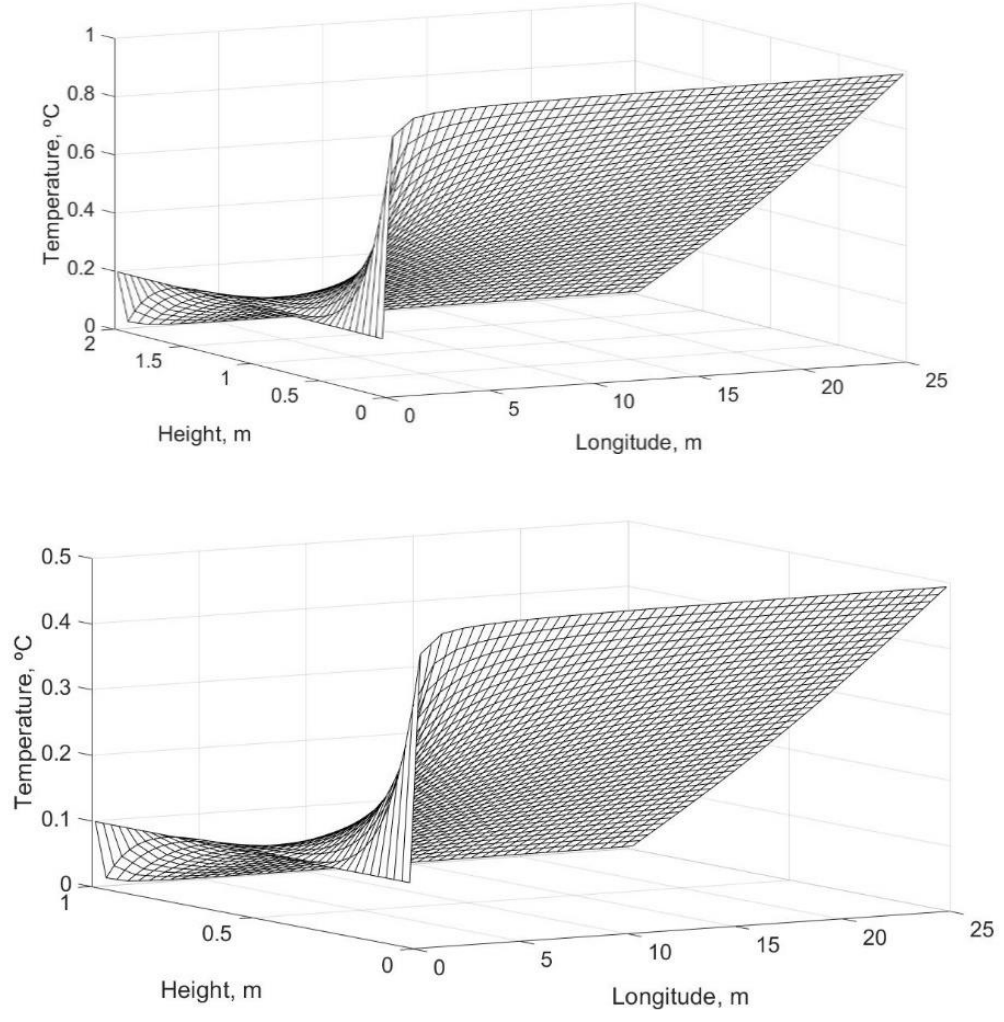

Figure 8. Temperature pattern of scenarios 1 to 3 (up) and 4 and 5 (down) 

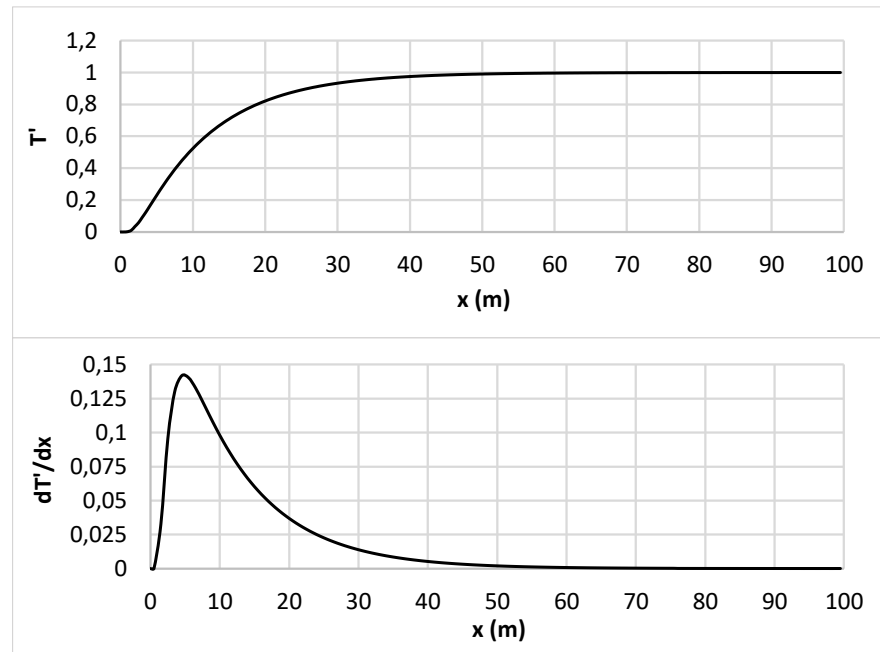

Figure 9. Dimensionless temperature profiles for Scenarios 1 to 5 at $y=H / 2$ (up). Horizontal temperature gradient (down)

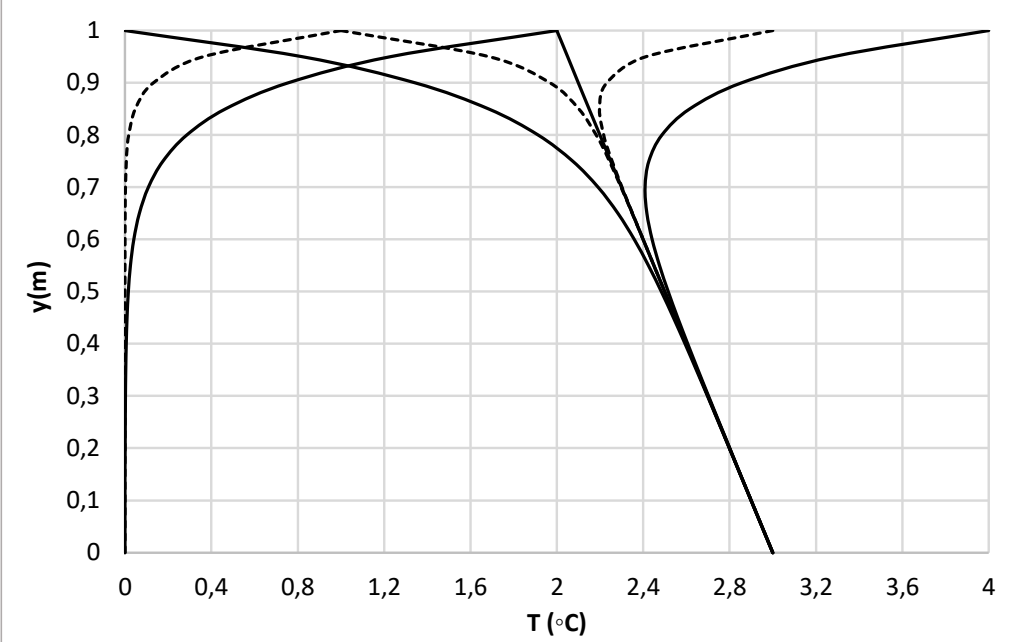

Figure 10. $\mathrm{T}_{\mathrm{av}}$ and envelopes of $\mathrm{T}_{\max }$ and $\mathrm{T}_{\min }$. Scenarios 6 (dashed) y 7 (continuous) 


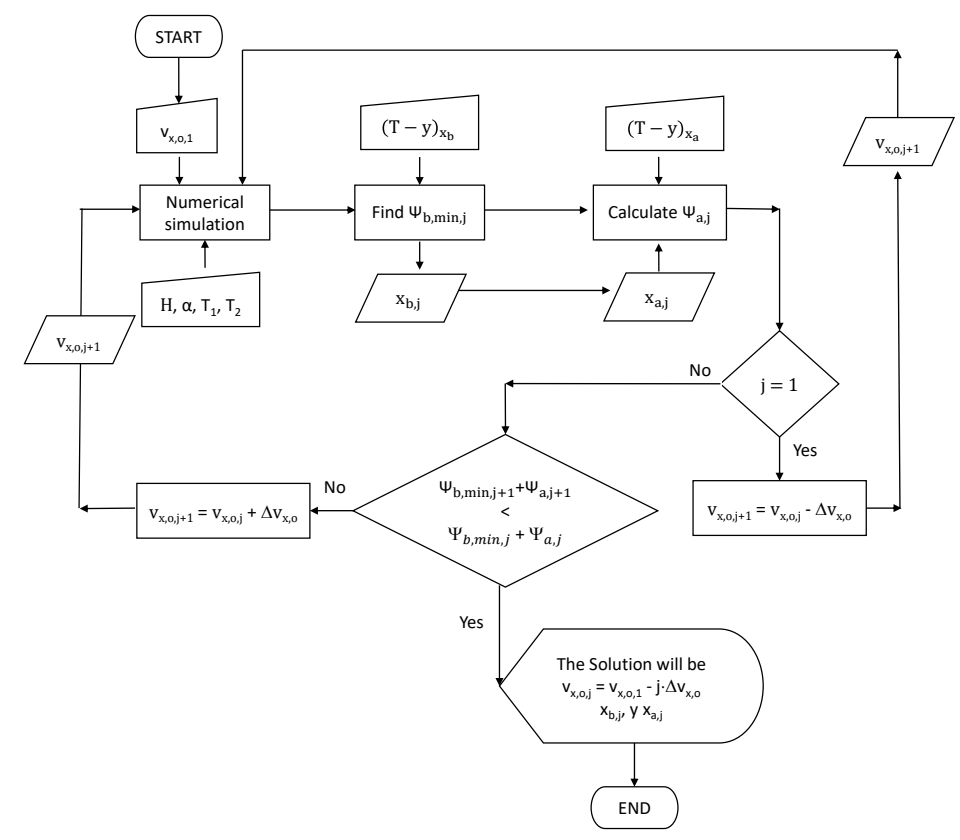

Figure 13. Block diagram of the inverse problem protocol 